\title{
Flow regime patterns and their controlling factors in the Ebro basin (Spain)
}

\author{
M. Dolores Bejarano ${ }^{a, *}$, Miguel Marchamalo ${ }^{b}$, Diego García de Jalón ${ }^{a}$, Marta González del Tánago ${ }^{a}$ \\ a Departamento de ingeniería Forestal, Unidad Docente de Hidrología, Universidad Politécnica de Madrid, E-28040 Madrid, Spain \\ ${ }^{\mathrm{b}}$ Departamento de Ingeniería y Morfología del Terreno, Universidad Politécnica de Madrid, E-28040 Madrid, Spain
}

Keywords:

Flow regime

Reference conditions

Hydrologic alteration

Flow classification

Prediction

Fluvial restoration

\begin{abstract}
S U M M A R Y
Natural intra-annual flow fluctuations vary between rivers, being a determining factor for aquatic insects, fish and riparian communities which are adapted to the habitat conditions and different flows throughout the seasons. Moreover, restoration of seasonal flow patterns plays an important role in achieving good ecological status of rivers, through the preservation and/or recovery of components and processes of natural river ecosystems. In this work we: (a) classify fluvial segments in the Ebro basin (North-Eastern Spain) according to the intra-annual variability of flows under natural conditions using statistical cluster analysis of monthly mean flow data; (b) characterise the resulting flow typologies according to several ecologically important hydrological variables; (c) analyse the relationships between flow regimes of fluvial segments and physical variables from their catchments; and finally (d) predict the most probable natural flow regime using logistic models based on the most determinant physical characteristics. Fifteen natural flow typologies were described in the Ebro basin, which were characterised in terms of flow fluctuation through the year as well as timing, flow ratio and duration of the maximum and minimum flows. Precipitation, biogeography and geology of catchments showed the highest correlations with flow regimes. Basin size, mean elevation and slope were also correlated. The logistic model we developed had a prediction success of $72 \%$ in the Ebro basin. The definition of the natural hydrological conditions (to which the biological communities are tailored), even when flow data are not available, is an important support in the management of river ecosystems. It is especially suitable for setting goals in aquatic ecosystem conservation or restoration projects.
\end{abstract}

\section{Introduction}

At present, few river flows remain unaltered. Dams are a major cause of hydrologic alteration. There are over 45,000 large dams around the world (greater than $15 \mathrm{~m}$ in height), retaining $15 \%$ of the total annual global unoff (Nilsson et al., 2005). The hydrological regime plays a major role in the preservation and restoration of the components and processes of the river ecosystems. Both directly and indirectly through its effect on the physical characteristics that underlie the biological communities, the hydrological regime affects the distribution of species, their adaptive capacity, as well as survival, dispersal and reproduction, and ultimately, the biodiversity, production and sustainability of river ecosystems (Poff et al., 1997; Bunn and Arthington, 2002; Arthington et al., 2006). Not only changes in the magnitude of the flows, but also of the frequency, duration, timing and/or rise/fall rates which are characteristic for a given river and constitute its "natural flow regime" (Poff et al., 1997), profoundly affect its flora and fauna (Ward and Stanford, 1979; Petts, 1984).

\footnotetext{
Corresponding author. Tel:; +34\$1336 6394.

E-mail address: mariadolores. bejaranoकupm.es (M.D. Bejarano).
}

The essential ecological role of the intra-anoual flow fluctuation has been highlighted by several authors. Life-listory adaptations of many fish, aquatic insects and riparian plants typically involve the synchronisation of life cycles-events in relation to the occurrence of annual flow regime events (Poff and Ward, 1989; Richter et al., 1996; Poff et al., 1997; Lytle and Poff, 2004). For example, natural timing of high or low stream flows provide environmental cues for initiation of life cycle transitions in fish, such as spawning, egg hatching, rearing, and movement onto the floodplain for feeding or reproduction, or migration upstream or downstream (Poff and Allan, 1995; Marchetti and Moyle, 2001; Freeman et al., 2001; Humphries, 2002). The seasonal sequence of flowering, seed dispersal, germination, and seedling growth of many riparian plants are also adapted to seasonal timing components of natura] flow regimes (Rood and Mahoney, 1990; Mahoney and Rood, 1998; Nilsson and Berggren, 2000). The emergence into an aerial adult stage and the diapauses of aquatic insects are related to seasonal floods and droughts (Hynes, 1970; Hancock and Bums, 1997).

Many works have linked intra-annual flow patterns of rivers to climatic conditions (Wilby, 1993; Hannah, 1998; Harris et al., 2000), and some have also shown the importance of geology, topograplyy, vegetative cover and river size (Poff et al., 1997; Baeza et al., 2005a). But, to what extent do the physical characteristics of 
the catchment determine certain seasonal flow behaviours in their fluvial segments? Is that physical information sufficient to characterise aquatic ecosystems?

In this paper we classify flow regimes in terms of their intra-annual seasonal fluctuation (what Harris et al., 2000 call "shape") for river reaches defined between tributaries in the Ebro river basin (Northern Spain) and we hydrologically characterise the resulting flow typologies. An analysis and discussion of associations between defined flow regimes and physical characteristics from catchments is also presented, so that, the relationships we found can be used to predict the most probable hydrological seasonal patterns for ungauged reaches or where no appropriate natural flow information exists.

\section{Testing area}

The Ebro river basin is the largest catchment in Spain. It extends over $85,530 \mathrm{~km}^{2}$ ( $17.3 \%$ of Spanish territory). It forms a broadly triangular morphological unit, bounded on the North by the Pyrenees and Basque-Cantabrian Mountains, to the East by the Catalan Coastal Chain, and from North-West to South-East by the Iberian Massif. From WNW to ESE until it reaches the Mediterranean Sea, it is drained by the $910 \mathrm{~km}$ long Ebro river. The drainage network has a total length of $12,000 \mathrm{~km}$ and it is much denser in mountainous areas (Fig. 1). Its location between the Eurosiberian and Mediterranean biogeographical templates makes it a heterogeneous basin. Its terrain includes rugged regions at the edges and flatter ground in the interior. Temperature variations are smoothed by the ocean in the Western half of the mountainous Northern bor- der, while continental climate dominates the depression. Average annual rainfall is $656 \mathrm{~mm}$, although it ranges from $300-500 \mathrm{~mm}$ annually in the centre to the $1500-2000 \mathrm{~mm}$ a year in the highest elevations of the catchment (http:// www.chebro.es; Bejarano et al., 2007).

The annual yield of the Ebro River is $18.2 \mathrm{~km}^{3} /$ year on average (maximum of $29.7 \mathrm{~km}^{3} /$ year and maximum of $8.4 \mathrm{~km}^{3} /$ year). Around $5-7 \mathrm{~km}^{3}$ are underground resources (for the period 1940-86 according to the Hydrological Plan for the Ebro river Confederación Hidrográfica del Ebro, 1999) mainly located in the Iberian Massif.

The basin is subjected to an intense exploitation of water resources. There are 216 large dams (Spanish Ministry of Environment, 2006) (Fig. 1), most intended mainly for hydropower production and for irrigation. Forty four percentage of the water bodies in the basin are impounded. The middle and lower stretches of the Ebro River are the most affected.

\section{Testing dataset and classification methodology}

As a characterisation and classification unit, the fluvial segment bounded by river confluences and its surrounding drainage area was selected, using the hydrographic network from topographic maps at a 1:50,000 scale. A total of 658 fluvial segments have been described in the Ebro basin (Bejarano et al., 2007), each one identified by a code following Verdin and Verdin (1999) (Fig. 2).

In order to classify the natural flow regime based on fluctuations along the year, a statistical cluster analysis in stages was conducted. For each fluvial segment in the basin, we considered 12

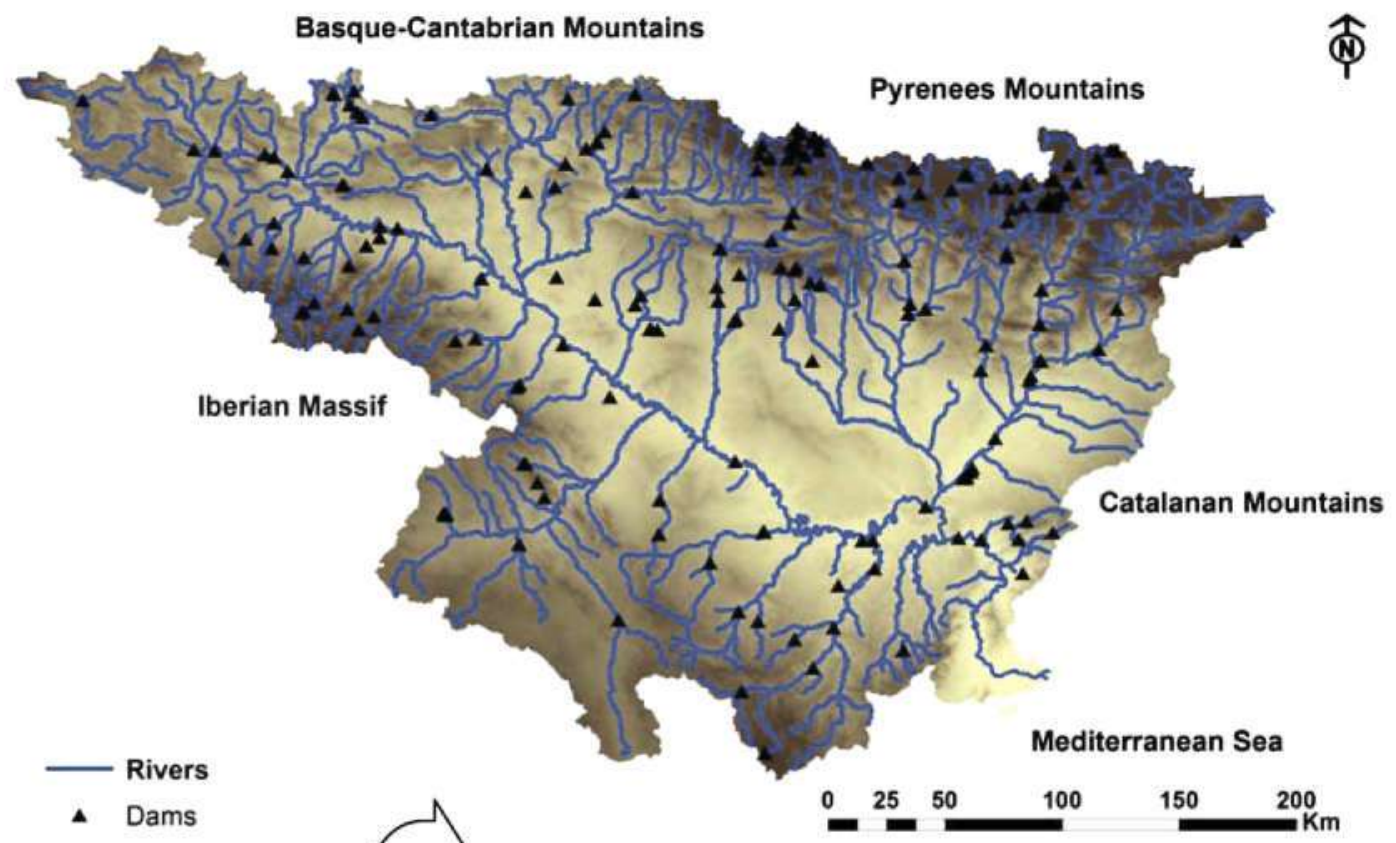

Fig. 1. Location map showing relief, river network and large reservoirs in the Ebro river basin in Northern Spain. 


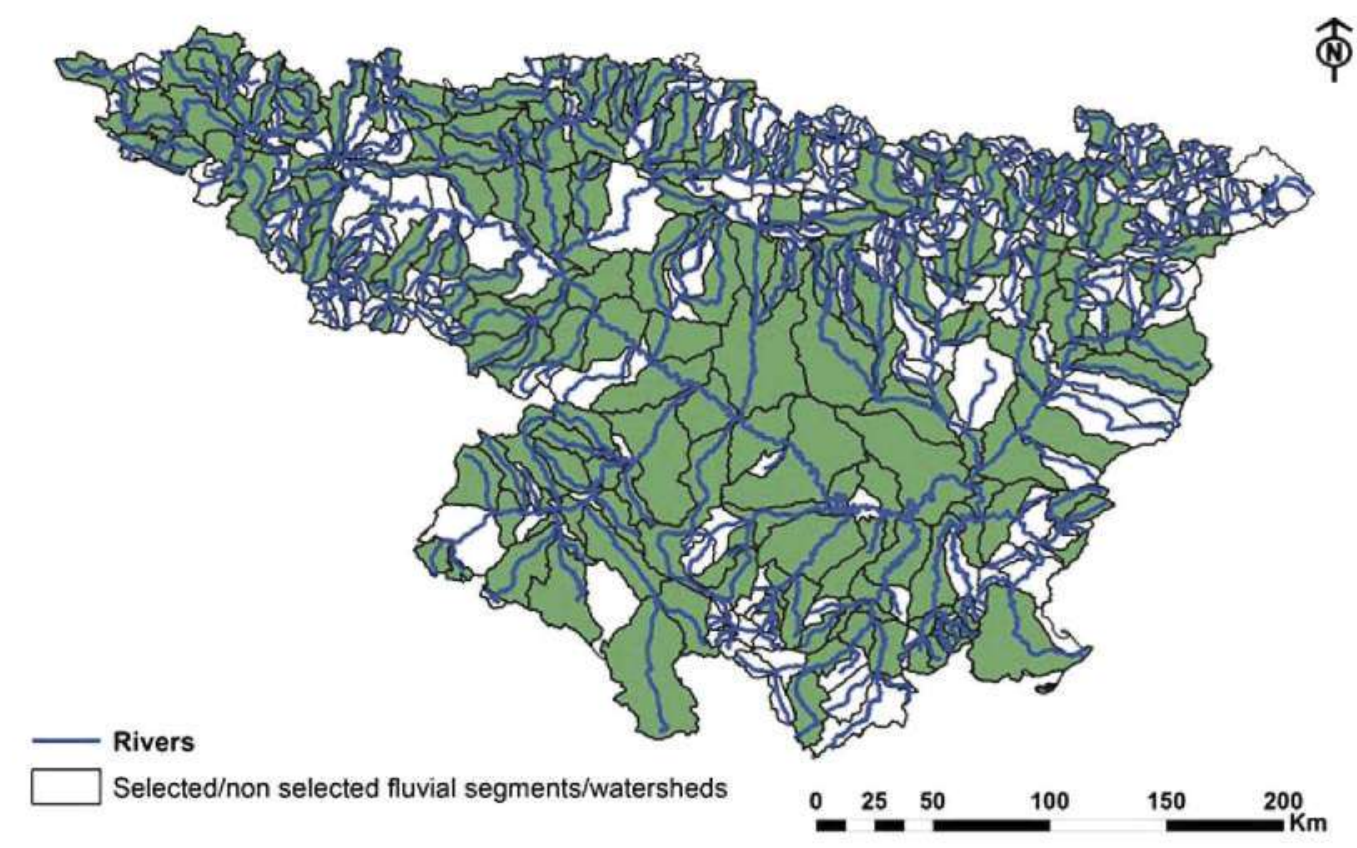

Fig. 2. Fluvial segments and respective catchments in the Ebro basin. Coloured catchments represent those selected for analyses of the relationships between physical and hydrological variables. (For interpretation of the references to colour in this figure legend, the reader is referred to the web version of this article.)

variables corresponding to the mean monthly flow standardised through the ratio between the average annual flow at the end of each fluvial segment, generated by SIMPA application for the period 1940/41-1985/86. Standardisation was used to eliminate the influence of the magnitude and allow comparisons. SIMPA is the Spanish acronym meaning "Integrated System for Rainfall-Runoff Modelling" (Sistema Integrado de Modelización de PrecipitaciónAportación). It is an application which includes several hydrological tools and models (see Témez, 1977; Estrela and Quintas, 1996 and Ruíz, 1998) developed in the Centre for Hydrographic Studies (CEDEX, Ministry of Environment and Public Works, Spain). It was designed to analyze spatial and temporal hydrological variables and to simulate hydrological processes based on them. Models cope with water resources, flood events or quality assessment. Among others, SIMPA has been used in Spain for water resources assessment for the National Water Master Plan in 2000. This information was provided by the Ebro Water Authority (Confederación Hidrográfica del Ebro. http:// www.chebro.es) and the National Water Research Centre (CEDEX. http://www.cedex.es). We measured the similarity between river segments represented in a 12 dimensions space (one per variable) using the Euclidean distance squared. The aggregation method used was the farthest neighbour. A cut-off distance between 12.3 and 26.4 was selected. This threshold for the identification of different seasonal flow patterns was set manually in the cluster dendrogram under the following premises: (a) to obtain a minimal number of types according to the aim of the classification, (b) but representing the heterogeneity of the basin including the full spectrum of flow fluctuations.

Subsequently, we characterised the resulting flow regimes. To do this, we selected 287 fluvial segments evenly distributed in the basin, ensuring representation of all resulting flow types (Fig. 2) and calculated a series of ecologically significant hydrological variables for each selected fluvial segment using the available mean monthly modelled flow data. The average of these variables for river typologies was obtained. Those variables analysed were:

1. Timing of absolute maximum flow (MaxAT): month in which the mean natural flow reaches the highest value (identifying months with numbers from 1 (October) to 12 (September) according to the hydrological year in Spain). If two or more consecutive months had the same maximum value, this corresponded to the average. If two or more non-consecutive months had the same value, this corresponded to the earlier month.

2. Timing of absolute minimum flow (MinAT): month in which the mean natural flow reaches the lowest value (identifying months with numbers from 1 (October) to 12 (September) according to the hydrological year in Spain). If two or more consecutive months had the same maximum value, this corresponded to the average. If two or more non-consecutive months had the same value, this corresponded to the earlier month.

3. Timing of secondary maximum flow (MaxST): in bimodal flow types (when the hydrograph shows two peaks of maximum flow), this is the month in which the mean natural flow equals the absolute maximum flow or it is up to $25 \%$ lower than this, having a period of lower flow of one to several months between both, absolute and relative maximum flows (identifying months with numbers from 1 (October) to 12 (September) according to the hydrological year in Spain).

4. Duration of period of maximum flow (MaxD): number of consecutive months around the absolute maximum flow, which have mean natural monthly flow values equal or up to $25 \%$ lower than absolute maximum flow.

5. Duration of period of minimum flow (MinD): number of consecutive months around the absolute minimum flow, which have mean natural monthly flow values equal or up to $25 \%$ more than absolute minimum flow.

6. Number of reversals calculated using monthly flow data (RN): number of rises and falls of the mean natural monthly flow throughout the year.

7. Ratio of the absolute maximum flow (MaxAR): how much higher the mean natural absolute maximum monthly flow was compared with the annual average flow.

8. Ratio of the minimum flow (MinAM): how much lower the mean natural absolute minimum monthly flow was compared with the average annual flow. 
Finally, a physical characterisation of catchments in the Ebro basin was carried out using available variables which can influence flow regime (González del Tánago and García de jalón, 2004). They were as follows:

1. Ecoregion, according to the Spanish Subprovince divisions (Rivas Martinez et al., 2002) which take into account mainly cljmatic and geological characteristics.

2. Precipitation regime. Characteristic anoual patterns of precipitation in the Ebro basin were analysed in a previous work by Bejarano et al. (2007). They found six patterns using a statistical cluster analysis with standardised mean monthly rainfall records from all meteorological stations in the basin for the same period as the flow data presented here. Their main characteristics are summarised in Table 1.

3. Basin size, following that proposed in the Water Framework Directive (European Commission, 2000).

4. Geology, according to categories described for Spain by Gutiérrez Elorza (1994) and suggested by the Water Framework Directive (European Commission, 2000), which imply distinct influence on runoff variability (Gustard, 1992; Sanz, 1996; Baeza and Marchamalo, 2002), as well as different solubility of rocks (related to water mineralization) and cohesion of the materials (related to grain size).

5. Меал elevation of the basin.

6. Slope of the fluvial segment.

Relationships between physical and hydrological variables in the 287 selected fluvial segments were analysed. The frequencies of fluvial segments for the categorical variables, both bydrological and plyysical, for each described flow type were analysed and organised in contingency tables. A Chi-square test was also carried out and the contingency coeficients were computed in order to understand the possible relationships between these variables and flow types. Statistical significance of median values for hydrological and physical numerical variables among the found flow typologies were tested using nол parametric Kruskal-Wallis analysis and by calculating the $H$ Kruskal-Wallis statistics. Afterwards, a multiple Comparisons of mean ranks was carried out for all groups to reveal which of the flow types were significantly different. To determine which relevant hydrological and physical variables were most related to seasonal flow behaviours and in order to reveal patterns in the data, Principal Component Analysis (PCA) was carried out: on the most significant hydrological variables which characterise the fluvial segments, and on the most relevant plyysical variables of catcluments. As most of plyysical variables were categorical, the frequencies of fluvial segments for each flow type in each category for each physical variable were used for the physical PCA analysis. Once relationships between flow types and physical variables were established in selected fluvial segments, we modelled the probability of each flow type occurring on the remaining 371 fluvial segments in the basin in relation to pluysical variables measured for their respective catchments using a Backwards Multiple Logistic Regression. We obtained a logistic model for each flow type estimating the likelihood of pertinence to the given type. The expected flow type for each fluvial segment was the one which slowed the highest probability of occurrence. The model was validated by comparing the resulting prediction with observed flow type from the previous cluster analysis on the flow data for the whole basin.

Statistical tests were performed with SPSS.10, Statgraphics plus.5.1. and Statistica.7 software.

\section{Results of classification in testing area}

\section{Flow regime classification}

Statistical cluster analysis provided a dendrogram (Fig. 3) which showed 15 types of natural intra-anıual flow patterns for the Ebro

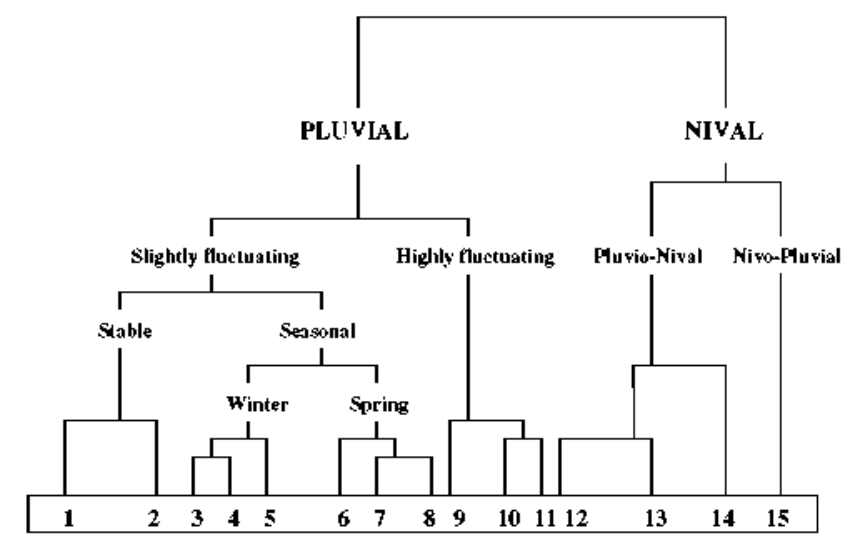

Fig. 3. Dendrogram from statistical Cluster analysis. $X$ axis contains the resulting flow types. Yaxis represents Euclidean distance square. Nival and Pluvial flow types are discriminated at the first level of the dendrogram linked mainly to snowmelt or rainfall influence respectively. At the second level of the dendrogram, on the Nival branch, rainfall progressively gains importance in Pluvio-Nival cypes, and on the Pluvial branch, highly and slightly fluctuating types are discriminated by the degree of intra-annual fluctuation. Slightly fluctuating flow types are divided into seasonal (winter or spring flow types) and stable typologies on the third and fourth levels of the dendrogram according to whether the period of maximum flow occurs at a certain season, or during a prolonged period in which the season is not very marked respectively.

Table 1

Precipitation regimes in the Ebro basin (from Bejarano et al, 2007)

\begin{tabular}{|c|c|c|c|c|c|}
\hline Precipitation regime & Rainy season & $\begin{array}{l}\text { Duration of rainy season } \\
\text { (number of months) }\end{array}$ & Dry season & $\begin{array}{l}\text { Duration of dry season } \\
\text { (number of months) }\end{array}$ & $\begin{array}{l}\text { Total annual } \\
\text { precipitation (mm) }\end{array}$ \\
\hline Eastern Pyrenees & $\begin{array}{l}\text { late surnmer } \\
\text { Spring }\end{array}$ & $\begin{array}{l}2 \\
2\end{array}$ & Winter & 2 & 1000 \\
\hline Westem Pyrenees & $\begin{array}{l}\text { Autumn } \\
\text { Spring }\end{array}$ & $\begin{array}{l}3 \\
2\end{array}$ & Summer & 2 & 900 \\
\hline Centre of Ebro basin & $\begin{array}{l}\text { Early autumn } \\
\text { Spring }\end{array}$ & $\begin{array}{l}3 \\
1\end{array}$ & Summer & 3 & 350 \\
\hline Cantabrian Mountains & $\begin{array}{l}\text { Autumn-winter } \\
\text { Spring }\end{array}$ & $\begin{array}{l}4 \\
2\end{array}$ & Summer & 2 & 1100 \\
\hline Nortluwestern lberian Massif & $\begin{array}{l}\text { late autumn } \\
\text { Spring }\end{array}$ & $\begin{array}{l}2 \\
2\end{array}$ & Summer & 2 & 650 \\
\hline Southeastern lberian Massif & $\begin{array}{l}\text { Autumn } \\
\text { Spring }\end{array}$ & $\begin{array}{l}2 \\
1\end{array}$ & $\begin{array}{l}\text { Winter } \\
\text { Summer }\end{array}$ & $\begin{array}{l}2 \\
2\end{array}$ & 500 \\
\hline
\end{tabular}



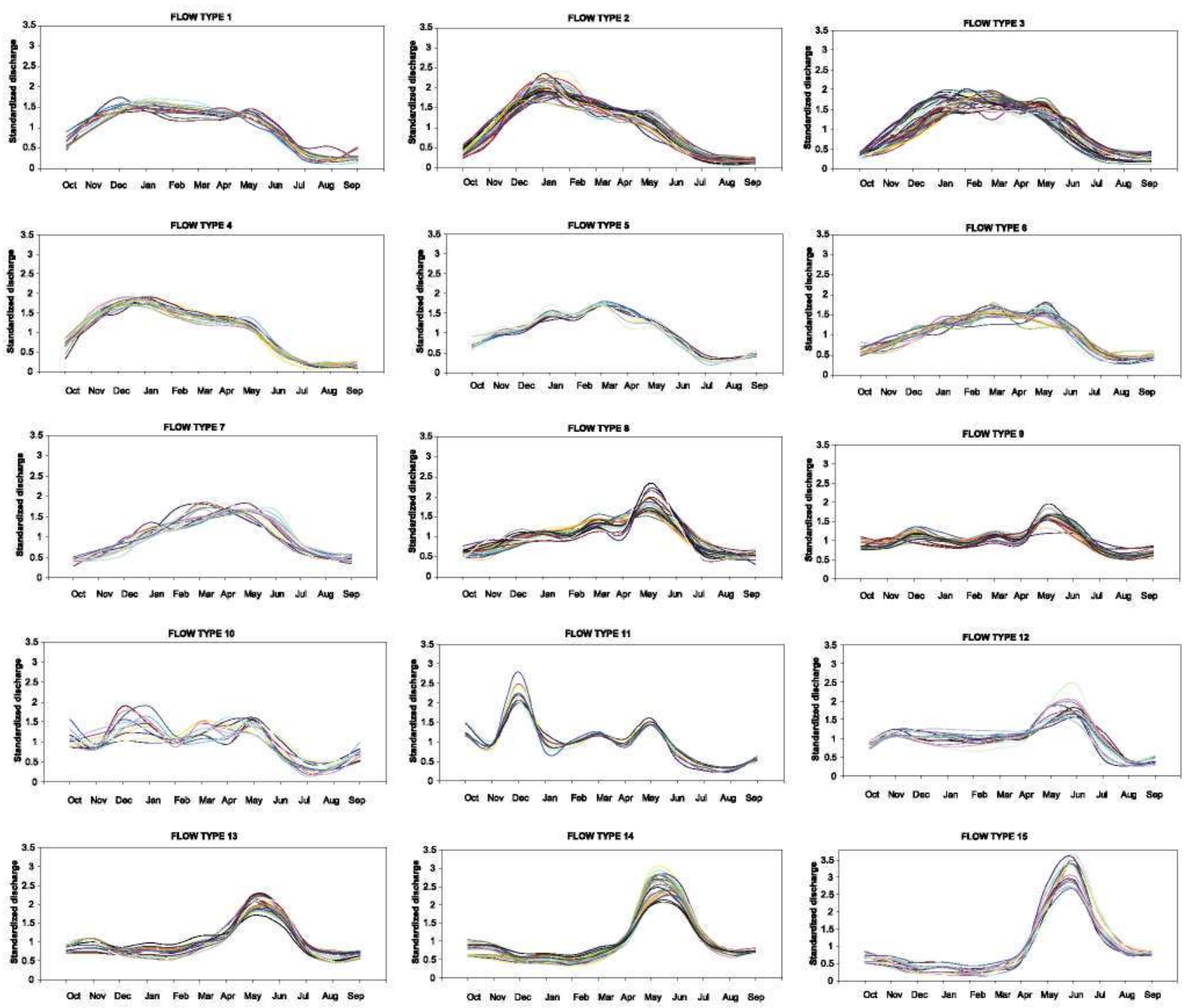

Fig. 4. Average annual pattern in mean monthly standardised discharge for each flow type in the Ebro basin.

basin (Fig. 4). A prior inspection of the graphs for discharge regime showed shape differences among typologies. Differences in timing, duration and flow ratios of high and low flows, presence or absence of secondary high flows, number of reversals (calculated using monthly flow data) and the sharpness or gentleness of a curve, could be distinguished. This was reflected in the analysed hydrological variables for each fluvial segment and flow types (Table 2).

Nival and pluvial typologies were discriminated at the first level of the dendrogram (Fig. 3). Nival types were characterised by late spring or even summer maximum flow much higher than mean annual flow but occurring during short periods. On the other hand, pluvial types presented not as marked maximum flows but over longer periods, and they usually showed up bimodal hydrographs with winter and spring absolute and secondary maximum flows. In terms of minimum flows, nival types usually presented longer low flow periods but not as marked as those for pluvial types. Timing was also a distinctive feature, in general minimum flows occurred during winter in nival typologies, while they were during summer in pluvial ones (Table 2 and Fig. 4).

The second level of the dendrogram divided nival and pluvial types into different groups. On the nival branch, flow type 15 , which represents nivo-pluvial segments, was soon differentiated from pluvio-nival typologies (Fig. 3). Nivo-pluvial segments showed the highest values for maximum flow ratio and one of the shortest maximum flow period. They also showed the longest minimum flow period. Although snowmelt influence is important in both groups, it is particularly significant in nivo-pluvial types, while rainfall progressively gains importance in pluvio-nival ones, from flow type 14 to flow type 12 . It was reflected as a decrease in maximum flow ratios and rise in duration of maximum flow period. Shorter minimum flow periods were also found as thawing lost significance (Table 2 and Fig. 4).

On the pluvial branch of the dendrogram, two main groups were distinguished mainly by the degree of intra-annual fluctuation (Fig. 3). Highly fluctuating types, which showed multipeak hydrographs, presented the highest number of rises and falls (calculated using monthly flow data) evenly distributed throughout the year. Duration of maximum flow period in fluctuating typologies was shorter compared with less fluctuating ones, however, most of them also showed very short minimum flow periods. Minimum flow ratio was also relatively higher in fluctuating types. Among the most fluctuating typologies, differences in absolute and secondary high flow timing allowed a clear separation of highly fluctuating flow type 9 from highly fluctuating flow types 
Table 2

Hydrological variables for flow types. Timing shows the month/s in which the maximum or minimum flows are achieved in more than $65 \%$ of the cases. The rest of the variables show the mean values and standard deviations for each flow type. MaxAT and MinAT represent timing of absolute maximum and minimum flows; MaxST represents timing of secondary maximum flow: MaxAR and MinAR represent absolute maximum and minimum flows ratios to the annual average flow; MaxD and MinD represent duration of maximum and minimum flows period; RN represents number of raises and falls (reversals) throughout the year calculated using monthly flow data.

\begin{tabular}{|c|c|c|c|c|c|c|c|c|c|}
\hline Flow type & & $\begin{array}{l}\text { MaxAT } \\
\text { (month) }\end{array}$ & $\begin{array}{l}\text { MaxAR (times } \\
\text { annual } \\
\text { average) }\end{array}$ & $\begin{array}{l}\text { MaxST } \\
\text { (month) }\end{array}$ & $\begin{array}{l}\text { MaxD } \\
\text { (number } \\
\text { months) }\end{array}$ & $\begin{array}{l}\text { MinAT } \\
\text { (montli) }\end{array}$ & $\begin{array}{l}\text { MinAR (times } \\
\text { annual } \\
\text { average) }\end{array}$ & $\begin{array}{l}\text { Mind } \\
\text { (number } \\
\text { months) }\end{array}$ & $\begin{array}{l}\text { RN (number } \\
\text { of l'aises and } \\
\text { falls) }\end{array}$ \\
\hline \multirow[t]{2}{*}{ Pluvial stable } & 1 & Jan & $1.57 \pm 0.089$ & May-Apr & $6.05 \pm 1.1$ & Aug & $0.233 \pm 0.045$ & $1.95 \pm 0.49$ & $2.571 \pm 0.926$ \\
\hline & 2 & Jan & $1.987 \pm 0.176$ & May & $3.82 \pm 1.16$ & Sep-Aug & $0.175 \pm 0.051$ & $1.79 \pm 0.65$ & $2.152 \pm 0.508$ \\
\hline \multirow[t]{3}{*}{ Pluvial winter } & 3 & $\begin{array}{l}\text { Mar-Feb- } \\
\text { Jan }\end{array}$ & $1.791 \pm 0.136$ & & $4.63 \pm 0.97$ & Sep & $0.266 \pm 0.07$ & $2.49 \pm 0.55$ & $3.073 \pm 1.33$ \\
\hline & 4 & Jan & $1.814 \pm 0.07$ & $\begin{array}{l}\text { May-Mar- } \\
\text { Арг }\end{array}$ & $4.13 \pm 0.89$ & Aug & $0.149 \pm 0.046$ & $1.88 \pm 0.72$ & $2.875 \pm 0.342$ \\
\hline & 5 & Mar & $1.712 \pm 0.049$ & & $4.1 \pm 0.57$ & Aug & $0.301 \pm 0.042$ & $1.8 \pm 0.42$ & $3 \pm 0$ \\
\hline \multirow[t]{3}{*}{ Pluvial spring } & 6 & May & $1.629 \pm 0.102$ & Mar & $4.53 \pm 1.41$ & Aug & $0.394 \pm 0.055$ & $1.93 \pm 0.7$ & $3.933 \pm 1.223$ \\
\hline & 7 & May & $1.737 \pm 0.095$ & Mar & $3.92 \pm 0.79$ & Sep & $0.403 \pm 0.048$ & $2.83 \pm 0.58$ & $2.167 \pm 0.577$ \\
\hline & 8 & May & $1.798 \pm 0.278$ & & $3 \pm 1.58$ & Aug & $0.525 \pm 0.084$ & $2.71 \pm 0.90$ & $2.762 \pm 0.944$ \\
\hline \multirow{3}{*}{$\begin{array}{l}\text { Pluvial highly } \\
\text { fluctuating }\end{array}$} & 9 & May & $1.577 \pm 0.136$ & Dec & $2.37 \pm 1.61$ & Aug & $0.606 \pm 0.085$ & $2.58 \pm 1.02$ & $7.158 \pm 0.765$ \\
\hline & 10 & $\begin{array}{l}\text { May-Dec- } \\
\text { Jan }\end{array}$ & $1.606 \pm 0.158$ & May-Mar & $2.46 \pm 0.88$ & Aug & $0.375 \pm 0.11$ & $1.92 \pm 0.64$ & $5.615 \pm 1.609$ \\
\hline & 11 & Dec & $2.289 \pm 0.299$ & May & $1 \pm 0$ & Aug & $0.31 \pm 0.049$ & $1.86 \pm 0.7$ & $8 \pm 0$ \\
\hline \multirow[t]{3}{*}{ Pluvio-Nival } & 12 & Jun & $1.754 \pm 0.244$ & Nov & $2.71 \pm 1.86$ & Aug & $0.347 \pm 0.06$ & $1.86 \pm 0.36$ & $5.357 \pm 0.929$ \\
\hline & 13 & May & $2.014 \pm 0.161$ & & $2 \pm 0$ & Feb-Aug & $0.691 \pm 0.119$ & $3.07 \pm 1.7$ & $5.393 \pm 1.031$ \\
\hline & 14 & May & $2.445 \pm 0.257$ & & $1.95 \pm 0.21$ & Feb & $0.477 \pm 0.091$ & $3.14 \pm 0.89$ & $4.591 \pm 0.666$ \\
\hline Nivo-Pluvial & 15 & Jun & $3.162 \pm 0.351$ & & $1.57 \pm 0.51$ & Feb & $0.29 \pm 0.105$ & $3.43 \pm 0.51$ & $3.214 \pm 0.579$ \\
\hline
\end{tabular}

10 and 11 . While absolute maximum flow occurred in spring and secondary flow in winter for flow type 9 , it was the other way around for the other two (Table 2 and Fig. 4).

Slightly fluctuating flow types were divided into seasonal and stable typologies on the third level of the dendrogram (Fig. 3). Stable typologies (flow types 1 and 2 ) showed very low values for maximum and minimum flow ratios and also for number of reversals of mean montluly flow values. They were both cluaracterised by long periods of maximum flow between winter and spring. A gradient of values for these variables from stable flow type 1 to stable flow type 2 could be distinguished, being the first one the most stable flow type in the Ebro basis. Maximum flow timing was the main difference between seasonal flow types. The fourth level of dendrogram basically differentiated typologies whose high flow occurred in winter from those of spring high flow. Stable flow type 2 could be in transition from the stable to seasonal winter flow type. Spring typologies also showed higher minimum flow ratios than winter typologies. Within each group, decreased gradient of duration of maximum flow period from winter flow types 3-5 and spring flow types 6-8 were observed (Table 2 and Fig. 4).
The Chi-square test confirmed a correspondence between categorical hydrological variables and the flow types described. The strength of this relationship was reflected in the high contingency coefficients and P-values smaller than 0.05 in all cases (Table 3). Multiple analyses of mean ranks revealed that, except for the duration of period of minimum flows, hydrological variables showed significant different values for most of flow types (Table 2 and Fig. 5). It was also corroborated by high values of the $H$ statistic from Kruskal-Wallis tests for numerical lyydrological variables for flow types in all cases except for duration of minimum flows period (Table 3). Seasonal winter flow type 5 shared most of its bydrological characteristics with others, being the weakest defined flow type. On the other hand, stable flow type 1 and nivo-pluvial flow type 15 were the most strongly defined, with most of their hydrological characteristics significantly different from the other flow types (Table 2).

PCA analysis discriminated between hydrological characteristics in flow types (Fig. 6). The principal component of PCA of lsydrological characteristics explained up to $43 \%$ of the variance. Together the first and second components accounted for $75 \%$ of

Table 3

Results for contingency coefficients and Kruskal-Wallis $\boldsymbol{H}$ statistics and respective P-values for studied hydrological and physical variables from catchments. MaxAT and MinAT represent timing of absolute maximum and minimum flows; MaxST represents timing of secondary maximum flow; MaxAR and MinAR represent absolute maximum and minimum flows ratios to the annual average flow: MaxD and MinD represent duration of maximum and minimum flows period: RN represents number of raises and falls (reversals) throughout the year calculated using monthly flow data.

\begin{tabular}{|c|c|c|c|c|}
\hline Variables & Contingency coefficient & Contingency coefficient $P$-value & H Kruskal-Wallis & Kruskal-Wallis P-value \\
\hline \multicolumn{5}{|l|}{ Hydrological } \\
\hline MaxAT & 0.86 & 0 & & \\
\hline MaxAR & & & 202.02 & 0 \\
\hline MaxST & 0.84 & $7.8 \times 10^{-10}$ & & \\
\hline $\operatorname{MaxD}$ & & & 183.21 & 0 \\
\hline MinAT & 0.81 & 0 & & \\
\hline MinAR & & & 238.21 & 0 \\
\hline $\operatorname{Min} \mathrm{D}$ & & & 96.66 & 0 \\
\hline $\mathrm{RN}$ & & & 198.99 & 0 \\
\hline \multicolumn{5}{|l|}{ Physical } \\
\hline Precipitation regime & 0.85 & 0 & & \\
\hline Ecoregion & 0.81 & 0 & & \\
\hline Geology & 0.68 & 0 & & \\
\hline Basin size & 0.63 & 0 & 9424 & 0 \\
\hline Elevation & 0.63 & 0 & 79.65 & $3.3 \times 10^{-11}$ \\
\hline Slope & 0.62 & 0 & 67.33 & $5.9 \times 10^{-9}$ \\
\hline
\end{tabular}



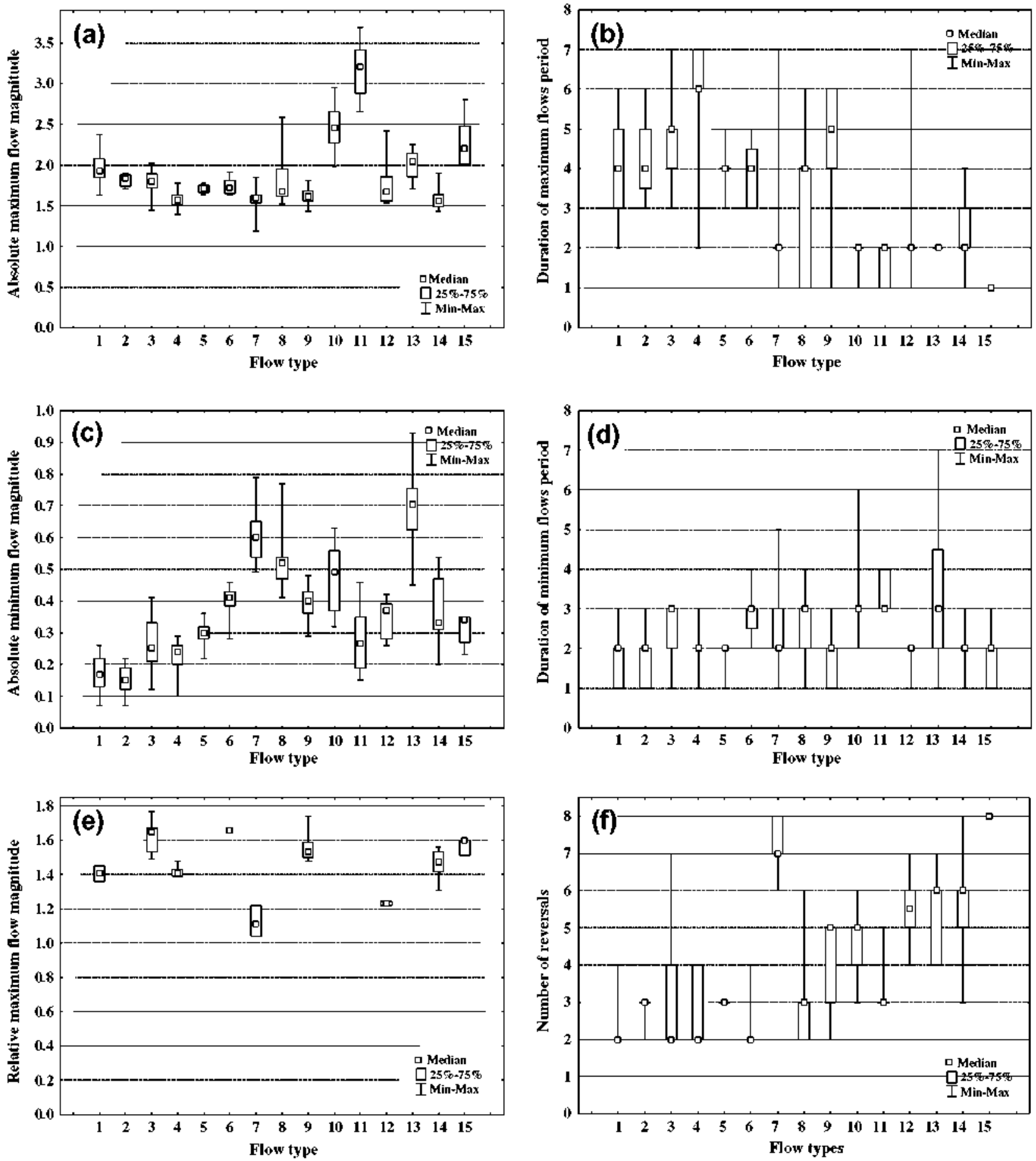

Fig. 5. Box and whisker plots of the annual median standardised absolute maximum flow (a), duration of period of maximum flow (b), standardised absolute minimum flow (c). duration of period of minimum flow (d), standardised relative maximum flow (e) and number of raises and falls (reversals) throughout the year calculated using monthly flow data (f), within each of the 15 flow types.

the total variance. While the first component represented timing and duration of maximum and minimum flows, the second identified flow ratios and number of reversals.

\section{Physical characterisation}

The pattern of spatial distribution of flow types described for the selected fluvial segments in the Ebro basin can be seen in Fig. 7. Frequency analyses showed that certain types of flow corresponded more closely to certain physical characteristics (Table 4).
At the highest and broadest level of the flow regime classification, flow typologies located in the Eurosiberian region were clearly separated from those flow types located in the Mediterranean region (Rivas-Martínez et al., 2002). This first division matched the nival and pluvial flow divisions respectively. Within Mediterranean region, particular climatic characteristics separated those flow types with the highest fluctuations from the others. They were located in the South-East of the Ebro basin (CatalanaValenciana Subprovince) and were characterised by fairly low total annual precipitation and prolonged diy season. Basin size allowed 


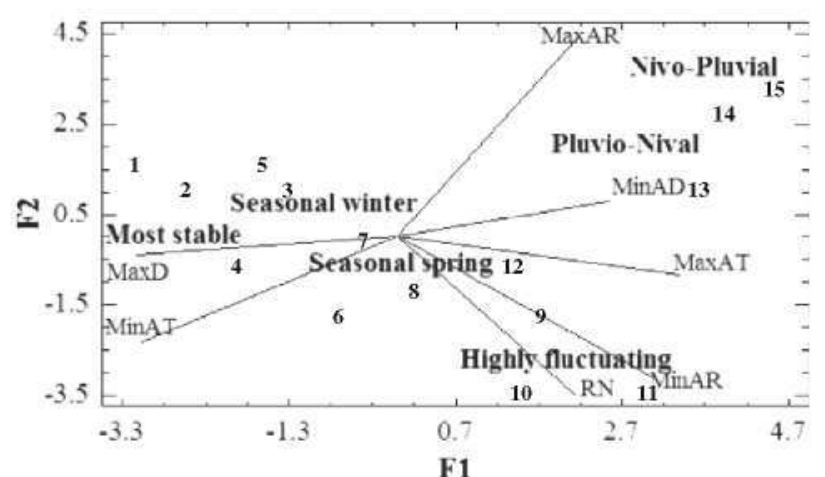

Fig. 6. PCA biplot of most significant hydrological variables: absolute maximum flow ratio (MaxAR), absolute maximum flow timing (MaxAT), duration of period of maximum flow (MaxD), absolute minimum flow ratio (MinAR), absolute minimum flow timing (MinAT), duration of period of minimum flow (MinD), and number of raises and falls (reversals) throughout the year calculated using monthly flow data (RN). Weight for hydrological variables and the dispersion of flow types are represented to first and second components (F1 and F2). F1 explains $43 \%$ of the tota variance and F2 explains $32 \%$ of the total variance. Maximum and minimum flows timing have been turned into numerical variables, from 1 (January) to 12 (December) in order to represent them on the graph.

differentiation of flow types in highly fluctuating branch. Among remaining pluvial flow typologies, spring seasonal ones were mainly distributed along the South-East side of the Iberian Massif (Oro-Ibérica Subprovince), where precipitation regime follows a gradient along the ridge from the inside edge to the Mediterranean Sea. A combination of basin size, elevation and slope enabled distinction between these three flow typologies. On the other hand, stable seasonal winter flow typologies were mainly located in North-West and centre of the Ebro basin. The most stable flow type (flow type 1), belonged to middle and lower catchments of Ebro river running through the centre of the basin (Bajo-Aragonesa Subprovince) and comprised, as was shown by Kruskal-Wallis test, the largest, flattest and lowest basins. Upstream contributions mean that this flow type does not reflect the driest zone in the basin. Sometimes, underground contributions could also explain flow sta- bility. Seasonal winter flow types, except for flow type 5 located in the centre, were found in the in the Northern part of Iberian Massif and along the Basque-Cantabrian Mountains (Oro-Ibérica and Cantabro-Atlántica Subprovinces). In general, they represented catchments which were not very steep nor high sided, most of them calcareous. They could be distinguished by the characteristics of ecoregion and precipitation regime, as they follow a gradient from North-West to South-East (Table 4).

Within Eurosiberian region, a gradient between flow types could be distinguished. On one side, nival types 14 and 15 were located in the Pyrenees Mountains (Pirenaica Subprovince (RivasMartinez et al., 2002)). This area is characterised by a snowy winter, very rainy spring and rainy late summer and autumn. Nevertheless, nivo-pluvial flow type 15 was soon distinguished, as shown by the Kruskal-Wallis test, as the smallest, steepest and highest catchments. On the other side, the remaining pluvio-nival flow types (12 and 13), were situated in the Pre-Pyrenees (among Pirenaica and Bajo-Aragonesa Subprovinces). This is a transition area where snowy winters progressively give way to rain, and summer is a dry season. Both presented mixed geology basins, larger than flow type 14 . Slight differences in elevation and slope allowed their differentiation (Table 4).

Chi-square analysis showed the relationship between the described flow types and some of the physical variables. Ecoregions and precipitation regime showed the highest values for the contingency coefficient among the analysed physical variables with an average of 0.8 . They were closely followed by geological characteristics of the catchments with 0.7 . Finally, values around 0.6 were shown for catchment size, elevation and slope (Table 3 ). KruskalWallis $H$ values for numerical physical variables and $P$-values lower than 0.05 suggested that there were some significantly different flow types (Table 3). Nevertheless, Multiple analysis of mean ranks showed that only the most stable flow type within the pluvial branch (flow type 1) and most of the nival types (flow types 1315) presented significantly different basin size, elevation and slope (Fig. 8).

PCA allowed differences between physical characteristics to be highlighted among fluvial segments of each flow type. The first

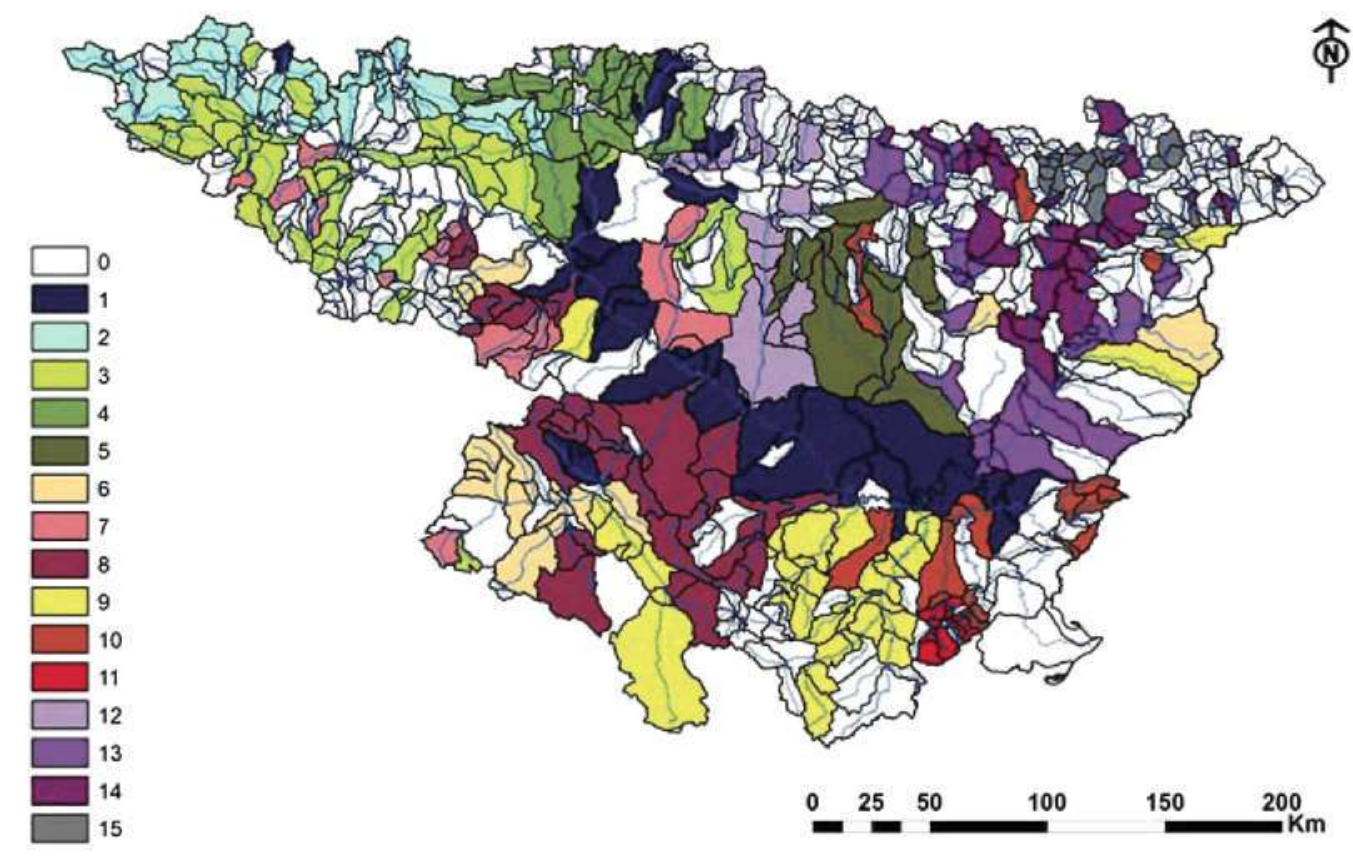

Fig. 7. Location in the Ebro basin of flow types of selected catchments for the analysis of relationships between hydrological and physical variables. Blank catchments represent the ones used for validation of the flow prediction model. 
Table 4

Physical description of flow types according to the frequency study. The most common characteristics which occurred in more than $65 \%$ of the catchments of each flow type are described. Basin size: small ( $\left.<99 \mathrm{~km}^{2}\right)$, medium $\left(100-999 \mathrm{~km}^{2}\right)$, large $\left(1000-9999 \mathrm{~km}^{2}\right)$ and very large $\left(>10000 \mathrm{~km}{ }^{2}\right)(W F D, 2000)$. Elevation: very low $(<399 \mathrm{~m})$, low $(400-$ $649 \mathrm{~m})$, medium $(650-849 \mathrm{~m})$, high $(85-1049 \mathrm{~m})$ and very high (>1050 m). Slope: very flat ( $0.19 \%)$, flat $(0.2-0.84 \%)$, medium $(0.85-2.49 \%)$, steep $(2.5-4.49 \%)$, very steep ( $>4.5 \%)$.

\begin{tabular}{|c|c|c|c|c|}
\hline Ecoregion and precipitation regime & & Geology & Basin size, elevation and slope & Flow type \\
\hline \multicolumn{5}{|l|}{ Meditersanean ecoregion } \\
\hline Middle and lower Ebro river & $\begin{array}{l}\text { Bajo-Aragonesa Subprov. Centre } \\
\text { of Ebro basin precipitation } \\
\text { regime }\end{array}$ & Mixed & Very large, very low, very llat & Flow type 1 \\
\hline Basque-Cantabrian Mountains & $\begin{array}{l}\text { Cantabro-Atlántica Subprov. } \\
\text { Cantabrian precipitation regime }\end{array}$ & Calcareous & $\begin{array}{l}\text { Large-medium size, medium } \\
\text { elevation, Mat }\end{array}$ & Flow type 2 \\
\hline \multirow[t]{2}{*}{ Northern Iberian Massif } & $\begin{array}{l}\text { Oro-Ibérica to Cantabro- } \\
\text { Atlántica Subprov. Nortliwestern } \\
\text { lberian Massif precipitation } \\
\text { regime }\end{array}$ & Mixed and Calcareous & $\begin{array}{l}\text { Medium size, medium elevation- } \\
\text { high, medium slope-steep }\end{array}$ & Flow type 3 \\
\hline & & & Medium size, medium elevation, flat & Flow type 4 \\
\hline \multirow[t]{4}{*}{ Centre of Ebro basin } & $\begin{array}{l}\text { Bajo-Aragonesa Subprov. Centre } \\
\text { of Ebro basin precipitation } \\
\text { regime }\end{array}$ & Mixed & $\begin{array}{l}\text { Large-medium size, low elevation, } \\
\text { flat }\end{array}$ & Flow type 5 \\
\hline & & Mixed \& Calcareous & $\begin{array}{l}\text { Medium size, elevation and slope. } \\
\text { Spring waters }\end{array}$ & Flow type 6 \\
\hline & & & $\begin{array}{l}\text { Small, medium elevation-high, } \\
\text { medium slope-steep. Spring waters }\end{array}$ & Flow type 7 \\
\hline & $\begin{array}{l}\text { Oro-Ibérica Subprov. Centre of } \\
\text { Ebro basin precipitation regime }\end{array}$ & Calcareous \& Mixed & $\begin{array}{l}\text { Large, high, medium slope. Spring } \\
\text { waters }\end{array}$ & Flow type 8 \\
\hline \multirow[t]{3}{*}{ Southern Jberian Massif } & $\begin{array}{l}\text { Catalana-Valenciana Subprov, } \\
\text { Southeastern lberian Massif } \\
\text { precipitation }\end{array}$ & & $\begin{array}{l}\text { Large, medium elevation, flat. 5pring } \\
\text { waters }\end{array}$ & Flow type 9 \\
\hline & & Calcareous & $\begin{array}{l}\text { Medium size, medium elevation-low, } \\
\text { steep }\end{array}$ & Flow type 10 \\
\hline & & & Small, medium elevation-high, steep & Flow type 11 \\
\hline \multicolumn{5}{|l|}{ Eurosiberian ecoregion } \\
\hline \multirow[t]{2}{*}{ Pre-Pyrenee and centre of Ebro basin } & $\begin{array}{l}\text { Pirenaica to Bajo-Aragonesa } \\
\text { Subprov. Western Pyrenee and } \\
\text { centre of Ebro basin regimes }\end{array}$ & Mixed & Large, high, medium slope & Flow type 12 \\
\hline & & & $\begin{array}{l}\text { Large, medium elevation, medium } \\
\text { slope-llat }\end{array}$ & Flow type 13 \\
\hline \multirow[t]{2}{*}{ Pyrenees Mountains } & $\begin{array}{l}\text { Pirenaica Subprov, Eastern } \\
\text { Pyrenee precipitation regime }\end{array}$ & Siliceous and mixed & Medium size,very high and steep & Flow type 14 \\
\hline & & Siliceous & Small, very high, very steep & Flow type 15 \\
\hline
\end{tabular}

component explained $28 \%$ of the total variance of the data and identified ecoregions, precipitation regime and geology. The second component identified basin size, slope and elevation, and explained $23 \%$ of the total variance (Fig. 9). Up to 10 components were necessary to explain the remaining $49 \%$ of variance in flow types by physical characteristics.

\section{Flow type prediction}

Taking into account the observed relationships between hydrological regimes and the studied physical variables in selected catchments, we predicted the natural flow regime of the remaining catchments in the Ebro basin using their physical characteristics. The backwards stepwise factor selection procedure within the Multiple Logistic Regression allowed us to select the most relevant physical variables for each flow type model. Precipitation regime patterns were selected in most of the models, while ecoregions were never selected for nival flow type modelling. Both physical varjables were the most influential in the generated models. Geology, basin size and elevation were selected as predictors in one third of the cases (Table 5). The highest values for the logistic analogue of $r^{2}\left(r_{1}^{2}\right)$ appeared at both ends of the dendrogram, in the most stable flow types $(1,2)$ and in the nivo-pluvial flow type 15 , with an average value of $60 \%$ (Table 5). This indicated that $60 \%$ of the uncertainty in assigning these flow types to each fluvial segment could be explained by a combination of the most relevant selected physical variables. Worst values for $r_{l}^{2}$ appeared for the seasonal spring flow type models. The comparison of "predicted" flow types with "observed" flow types for each of 371 fluvial segments showed an error of $28 \%$ in the flow type prediction. Nival flow typologies presented the highest prediction errors in the Ebro basin.

\section{Discussion and conclusions}

Statistical cluster analysis is a very useful tool for the distinction of different patterns in a dataset. In this study, it allowed us to classify the natural annual standardised lyydrographs present in the Ebro basin into homogeneous groups using only readily available mean monthly flow records. This method was first successfully applied to climatological classifications (Kalkstein et al., 1987). It has since been used for the identification of distinct fish assemblages in Europe (Melcher et al., 2007). ln a flow regime context, this methodology was the main tool for classification of flow patterns used by Harris et al. (2000) and Hannah et al. (2000). Both authors analysed "shape" and "magnitude" of flow. As we work with standardised flow, magnitude is not taken into account in our study, and we focus on a deeper analysis of the slape of bydrographs and their relationships with several plyysical variables from catchments. On the other hand, while Hannah et al. (2000) used daily scale flow records, Harris et al. (2000) used, as we do here, monthly scale flow records. Since the research is focused on the intra-anumal fluctuation of flow and its final goal is to be able to predict, using physical variables, this seasonality (throughout the year), simplicity was 

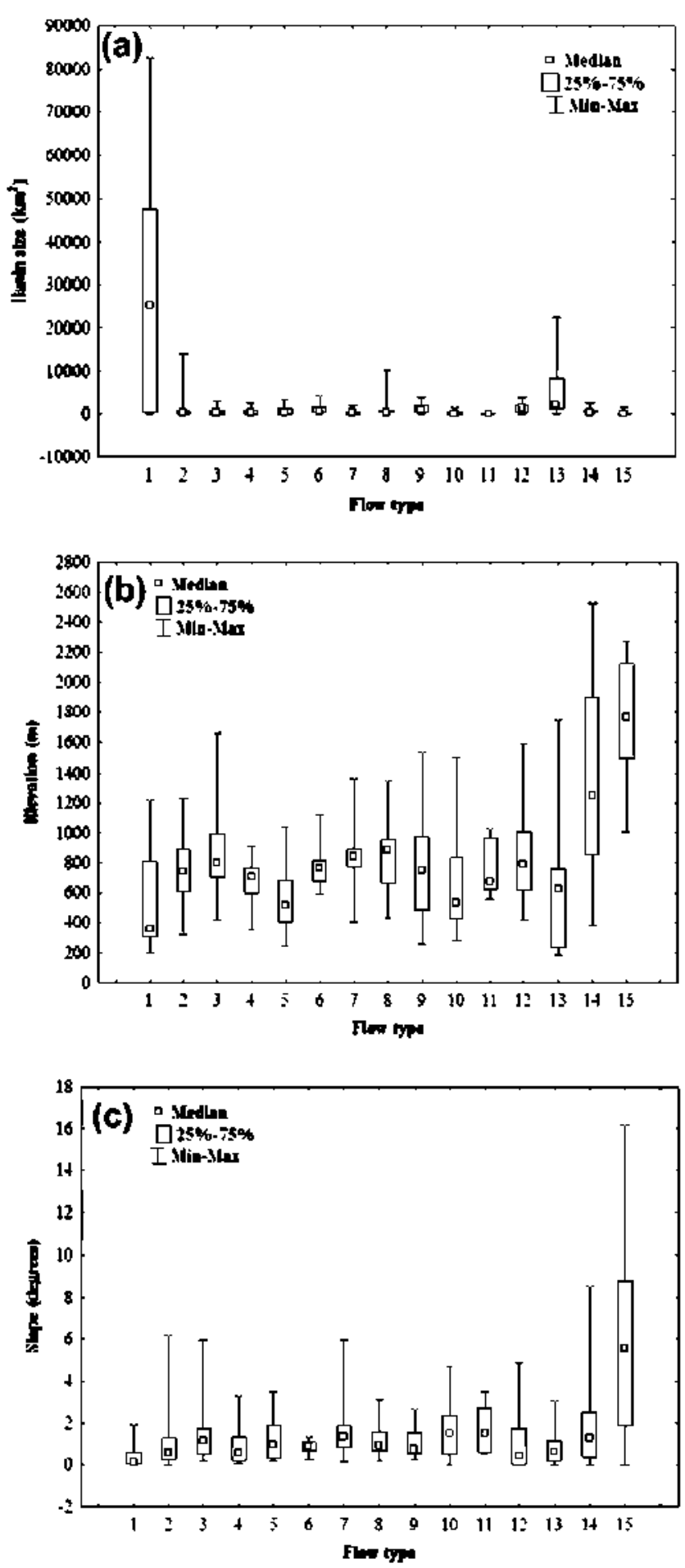

Fig. 8. Box and whisker plots of catchment size (a), mean elevation (b) and slope (c), within each of the 15 flow types.

required. Monthly flow series were thought to be accessible, easy to work with, and good representatives of the seasonality of flow, fitting the requirements of the work. Actually, the bydrological parameters calculated in this paper confirm that monthly data contain significant information to distinguish different intra-annual flow behaviours.

The definition of a relative high number of flow regimes for the Ebro basin (Fig. 4) could be the result of the temporal and spatial variability which characterise the Mediterranean environment. The study basin has great pluysical heterogeneity, which bas been shown to be a deciding factor in the annual seasonality of flow. The post-cluster hydrological characterisation of resulting flow types (Table 2), showed that key hydrological variables on which fluvial ecological processes depend, were significantly different, supporting the choice of the cut-off distance in the dendrogram and thus the 15 obtained typologies (Fig. 3 ).

The critical role of hydrological variability in sustaining aquatic ecosystems, has been showı in several studies (Poff et al., 1997; Richter et al., 1996). In order to provide information on ecologically significant features of intra-annual flow regimes, influencing aquatic, wetland and riparian ecosystems, we selected eight variables for the characterisation of the shape of the hydrographs from the different flow typologies (Table 2), supported by studies of relevant hydrological variables (see for example Richter et al., 1996; Olden and Poff, 2003; Baeza and García de Jalón, 2005b). Summer droughts are common in Mediterranean catchments, and only those located on the Eurosiberian side of the Ebro basin differ from this pattern. Hence, timing and duration of low flows allows differentiation between nival and pluvial flow typologies, however, they are not significant variables within Mediterranean environments. The same is true for secondary maximum flow, which only appears in pluvial Mediterranean typologies. So, it is useful in distinguishing between Eurosiberian and Mediterranean flow types, but it is not so useful for Mediterranean ones. On the other band, variables related to high flow and fluctuation degree valy significantly from one type to another. High and low flow ratios are also defining variables allowing separation of the more stable flows which remain around the average for much of the time, from those whose maximum or minimum flows deviate considerably from the annual average (Fig. 6).

The important influence of several physical characteristics of the catchments on flow regimes is demonstrated in this paper (Table 5). We also show that there is a hierarchy in the importance of such physical factors, and that each one may be mainly responsible for the response of certain hydrological parameters. Rainfall patterus and biogeographical characteristics explain, at the first levels, differences among flow typologies. But, more precise flow regime classification is only possible if beyond these, other physical factors such as geological nature of catchments, size, elevation and slope, are also taken into account (Table 4, Figs. 6 and 9).

The first level of the flow regime classification in the Ebro basin, which separates Eurosiberian nival from Mediterranean pluvial flow types, is clearly linked to biogeography of the catchments (Fig. 3). Duration and timing of low flows are the most important hydrological variables at this level having opposite responses in the two groups. Snowfall and thawing are the main factors responsible for the typical hydrograph shape of Eurosiberian catchments, characterised by prolonged low flow during winter and short but marked increases of flow in late spring. Nevertheless, summer droughts characterise Mediterranean types of flow (Tables 2 and 4). Biogeography and rainfall patterns are the determining factors at the second level of classification (Fig. 3), and their influence is revealed in some of the studied hydrological variables, highlighting the number of reversals throughout the year (calculated using montlyly flow data) and timing of maximum flows. Within nival types, a gradient is observed from nivo-pluvial to pluvio-nival flow typologies. The former are located in the Pyrenees themselves, while the latter are found in catchments in the foothills of the Pyrenees and centre of the basin where consequences of snowmelt are less important and flow regime shapes the clange from nival to seasonal patterns, presenting longer but less pronounced bigh flows and not only dry winters but also dry summers. Within pluvial types, clear differences can be recognised between Southeastem Mediterranean flow regimes and Northern and Nortlowestern flow regimes. Multipeak flow regimes characterised the former, presenting the lighest number of reversals (from monthly flow 


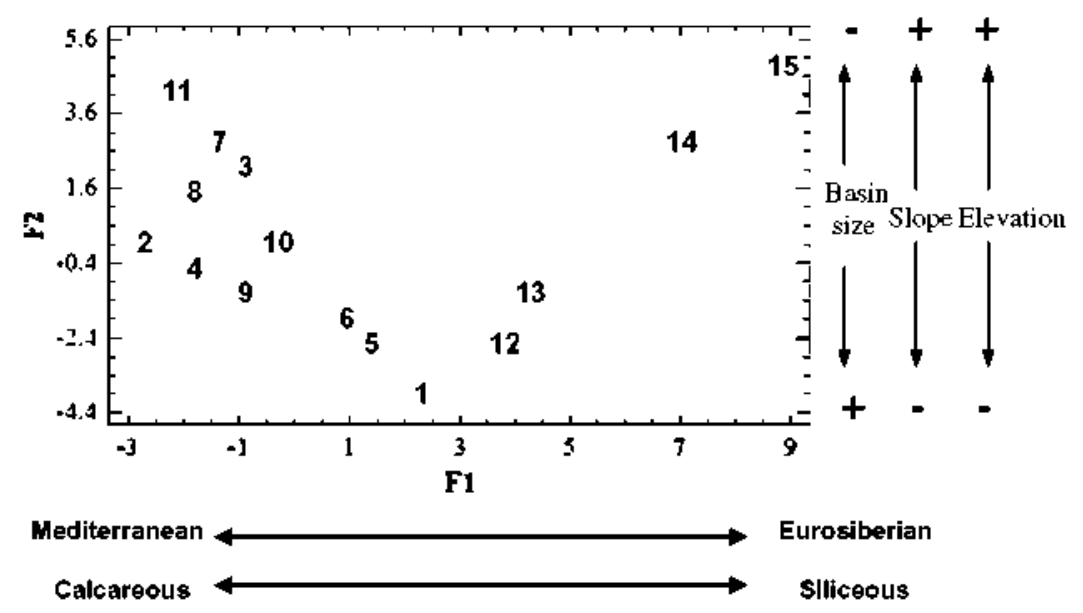

Fig 9. PCA biplot of significant physical variables. Weight for plyysical variables have been simplified for better understanding. The dispersion of flow cypes according to first and second components is also represented (F1 and F2). F1 explains $28 \%$ of the total variance of the data and F2 explains $23 \%$ of the total variance.

Table 5

Values fol the logistic colrelation coefficient and weight for the physical variables used in each logistic model for flow cype prediction. Ecoregions: Pirenaica (PI), Bajo-Aragonesa (BA), Cantabro-Atlántica (CA), Castellana (C), Oro-Cantábrica (OC) and Oro-Ibérica (Ol). Precipitation regime; Eastern Pyrenees (EP), Western Pyrenees (WP), Centre of Ebro basin (CB), Cantabrian Mountains (CM) and Northwestem Iberian Massif (NWIM).

\begin{tabular}{|c|c|c|c|c|c|c|c|c|c|c|c|c|c|c|c|c|c|c|}
\hline \multirow{2}{*}{$\begin{array}{l}\text { Flow } \\
\text { type }\end{array}$} & \multirow{2}{*}{$r_{t}^{2}$} & \multicolumn{6}{|c|}{ Ecoregion } & \multicolumn{5}{|c|}{ Precipitation regime } & \multicolumn{3}{|c|}{ Geology } & \multirow[t]{2}{*}{ Elevation } & \multirow{2}{*}{$\begin{array}{l}\text { Basin } \\
\text { size }\end{array}$} & \multirow[t]{2}{*}{ Slope } \\
\hline & & P] & $\mathrm{BA}$ & $C A$ & $c$ & OC & ol & EP & WP & $\mathrm{CB}$ & $\mathrm{CM}$ & NWIM & Mixed & Clay & Calcareous & & & \\
\hline 1 & 0.6 & 28.7 & 26.8 & 24.5 & 13.6 & 9.0 & 24.1 & -8.9 & -8.8 & 6.3 & 10.8 & 10.8 & & & & & 0.0003 & \\
\hline 2 & 0.7 & & & & & & & 0.9 & 1.7 & 14.5 & 21.2 & 17.4 & -3.8 & -0.6 & -2.2 & -0.0041 & & \\
\hline 3 & 0.5 & -1.1 & 14.1 & 13.6 & 15.5 & -2.6 & 15.3 & -10.4 & -11.2 & 1.2 & 2.4 & 3.6 & & & & & -0.0004 & \\
\hline 4 & 0.4 & & 0.1 & 17.3 & -0.4 & 16.5 & -1.5 & 0.1 & -0.9 & -1.4 & -1.6 & 17.3 & 16.0 & 15.5 & -0.6 & & & \\
\hline 5 & 0.3 & & & & & & & 1.7 & 1.4 & 17.9 & -0.1 & 0.0 & & & & -0.0036 & -0.0007 & \\
\hline 6 & 0.3 & -16.6 & -1.8 & -16.6 & 2.5 & -16.6 & -1.4 & & & & & & & & & & & \\
\hline 7 & 0.1 & 0.0 & 16.3 & -0.1 & 16.6 & 0.1 & 16.5 & & & & & & & & & & -0.0010 & \\
\hline 8 & 0.2 & & & & & & & -20.1 & -19.9 & 0.3 & -17.9 & -3.6 & -0.9 & -1.7 & 0.8 & 0.0030 & & \\
\hline 9 & 0.3 & 17.6 & 18.6 & 17.4 & -0.1 & 16.7 & 17.0 & -21.0 & -20.9 & -2.3 & -17.7 & -18.1 & & & & 0.0029 & & \\
\hline 10 & 0.4 & & & & & & & 1.3 & -15.5 & -1.2 & -16.8 & -0.00 & & & & -0.0070 & -0.0017 & 0.7349 \\
\hline 11 & 0.5 & & & & & & & -19.1 & -19.4 & -17.1 & -19.2 & -19.2 & & & & & -0.0069 & \\
\hline 12 & 0.4 & & & & & & & 0.3 & 18.8 & 15.8 & -0.2 & 0.1 & & & & & & -0.4839 \\
\hline 13 & 0.3 & & & & & & & 17.0 & 18.9 & 16.8 & 0.2 & 0.1 & & & & -0.0023 & & \\
\hline 14 & 0.4 & & & & & & & 18.7 & 17.1 & 14.8 & & & & & & & & \\
\hline 15 & 0.6 & & & & & & & & & & & & -18.2 & -18.5 & -18.5 & & & 0.3319 \\
\hline
\end{tabular}

data) along the year. It is often found that temporary fluvial segments belong to these flow types. Less fluctuating seasonal flow patterns characterised the latter, which usually present absolute and secondary maximum flows synchronised with rainy seasons and lower number of reversals (Tables 2 and 4 ).

At a lower level in the classification, flow regimes basically reflect the influence of the geological nature of catchments and their size (Fig. 3). Maximum and minimum flow ratios and duration of high flow periods are the most significant hydrological variables at this level. [n general, the most stable typologies, whose monthly mean flows are maintained around the annual average most of the year, coincide with largest mixed catchments. On the other hand, stable types with slightly gradual rises of flow from autumn through to May are also linked to calcareous catchments, most of them with underlying aquifers in which rainfall only contributes effectively to increased flow rates when they become saturated (Gustard, 1992; Sanz, 1996; Baeza and Marchamalo, 2002). Both of them present low values for flow ratios and long maximum flow periods (Tables 2 and 4). Finally, incorporating other physical variables from catchments, such as elevation and slope, at the lowest levels of the classification, allows to us to exclusively characterise the different flow regimes, making flow classification more accurate.
Based on the hierarchical relationships between plsysical and hydrological characteristics shown in this paper, predictive models of the most likely flow regime in a given fluvial segment can be developed. Nevertheless, although precipitation regime, biogeography or even geology of catchments strongly influence the flow regime (Table 5), correlation between physical factors and flow regimes becomes weaker as we descend the classification tree, when other plyysical variables are taken into account (Fig. 3 and Table 3). This may be the reason why, in the Ebro basin, certain flow regime types were difficult to distinguish from one another (mainly between nival flow types), although these errors only occurred at the lowest level of the classification tree. On the other hand, it has been slown that flow regimes are not simply the consequence of a few factors, but are the result of a combination of several (Fig. 9). Losing accuracy in prediction of flow typologies at the lowest levels of classification may lead to errors in predicting some ecologically relevant hydrological variables. For this reason, when flow data is available, it would be advisable to incorporate them into the classification. Those classification systems that only use physical variables, such as System $A$ in the Water Framework Directive (European Commission, 2000), ruı the risk of missing some important ecological features of the hydrological regime. But, when natural flow series are not available, characteristics of 
the natural flow regime of a fluvial segment could be defined using physical information from its catchment. Therefore, the underlying hierarchical physical characterisation of the basin is an important tool for river flow classification. Although particularities are taken into account, it is important to be mindful that any classification system remains a systematic reduction of reality and, that rivers are continua of flow, matter and energy (Vannote et al., 1980). In order to avoid ал excessive number of flow typologies and a very complicated predictive model driven by the use of many categories for the physical variables taken into account, we used a simple categorization for each variable based on previous characterisation and classification works which, using similar categories (Garcia de jalón et al., 2006), have resulted in ecologically meaningful river types.

Nowadays, many rivers bave their seasonal flow patterns altered because of the influence of upstream dams. As the ecology of permanent hydrosystems are very dependent on the intra-annual flow pattern, the presented analysis of its most important controlling factors and the final proposal of flow regime classificatіол methodology are ecologically relevant since they are able to define the characteristic "shape" of the natural annual hydrograph in river reaches thereby setting their hydrological reference conditions. This work is intended for use in the assessment of river ecosystems status, planning river management strategies, and setting and measuring progress toward conservation or restoration goals.

Environmental flow desigus at the regional scale can specially rely on the results of this classification. If flow alteration-ecological response relationships hold true for each member of a distinctive hydrological class and each type of flow alteration, then environmental flow 'guidelines' or 'rules' could be developed and applied to all rivers of that class (Poff et al., 2010), thereby avoiding the need to develop such relationships and standards for each indjvidual river within the class. However, reference conditions on seasonal flow fluctuation are only a part of the definition of ecological flows. Flow fluctuates in time not only throughout the year, but also throughout a montls or throughout a day. Therefore, daily or/and hourly flow series are recommended for the complete understanding of natural flow variations and trends. This more precise flow information is also needed when rise and fall rates want to be taken into account (especially downstream of lyydropower production dams). Flow magnitude is another important hydrological feature which should be added when defining ecological flows. It has been related to bаsin size іл other works, but this iлflueлce is missed in our study since we use standardised flows. Nevertheless, the influence of basin size on flow stability is emphasised in this paper. The definition and implementation of the environmental flows in rivers are key to restore and/or preserve the biophysical components and ecological processes involved in aquatic ecosystems (Arthington and Pusey, 2003). Hence, this method results in a useful tool for river restoration and river management in general. Water planning for major water bodies is taking place in Spain, for which this methodology will be useful. It is also applicable for use in other countries. EU member states for example, under the guidelines of the European Water Framework Directive (European Commission, 2000), must ensure the improvement of ecological status of their water bodies by 2016 .

\section{Acknowledgements}

The study has been possible thanks to the María Dolores Bejarano FPU Contract (AP2005-2680) for the training of university staff from the Spanish Ministry of Science and Iллоvation, and to the funds from the POTECOL Project (CCL2007-66412) fлалсеd by the Spanish Ministıy of Science and lnnovation. We also would like to thank Carlos Alonso and Joaquín Solana for their support with the statistical analyses, and Benedict Gove for his help with language corrections.

\section{References}

Arthington, A.H., Bunn, S.E., Polf, N.L., Naiman, R.,. 2006. The challenge of providing environmental flow rules to sustain river ecosystems. Ecol. Appl, 16, 13111318 .

Arthington, A.H., Pusey, B.J., 2003. Flow restoration and protection in Australian rivers. River Res, Appl, 19 (5-6), 377-395.

Baeza, D., Marchamalo, M., 2002. Una nueva metodología para calcular caudales ecológicos en la cuenca del Tajo. Equipamiento y Servicio Municipales, 2002 Ene,-Feb. Año19(99). Madrid, España, pp. 65-71

Baeza, D., García de Jalón, D., Gutiérrez, B., Vizcaíno, P., 2005. Basin influence on natural variability of rivers in semi-arid environments. J. River Basin Manage. 3 (2), 1-13.

Baeza, D., García de Jalón, D., 2005. Characterisation of streamflow regimes in central 5pain based on relevant hydrobiological parameters. J. Hydrol. 310, $266-279$.

Bejarano, M.D., García de Jalón, D. Marchamalo, M., 2007. Hierarchical characterization and classification of the Ebro river basin. Unpublished DEA from Ph.D. Thesis, Polytechnic University of Madrid, Spain.

Bunn, 5.E., Arthington, A.H., 2002. Principles and ecological consequences of altered flow regimes for aquatic biodiversity. Environ. Manage. 30, 492-507.

Confederación Hidrográfica del Ebro, 1999. Hydrological Plan for the Ebro river basin, BOE 222. September the 16th, pP. 33386-33452.

Estrela, T., Quintas, L., 1996. El sistema integrado de modelización precipitaciónaportación SIMPA. Revista de Ingeniería Civil. CEDEX (Ministerio de Fomento) $104,43-52$.

European Commission, 2000. Directive 2000/60/EC of the European Parliament and of the Council of October the 23rd Establishing a Framework for Community Action in the Field of Water Policy. OJEC (Official Joumal of the European Communities), p. 72

Freeman, M.C., Bowen, Z.H., Bovee, K.D., Iıwin, E.R., 2001. Flow and habitat effects on juvenile fish abundance in natural and altered flow regimes. Ecol. Appl. 11, $179-190$.

García de Jalón, D., González del Tánagoo, M., Marchamalo, M., Alonso, C., Baeza, D., 2006. Typology and reference conditions: a proposal for the Navarlás rivers network. In: Proceedings of the lll International 5ymposium on Transboundary Waters Management. Ciudad Real, Spain, 30 May-2 June, 2006.

González del Tánago, M., García de Jalón, D., 2004. Hierarchical classification of rivers: a proposal for eco-geomorphic characterization of Spanish rivers within European Water Frame Directive. In: García de Jalón, D., Vizcaino, P., (Eds.) Proceedings of the Sth International Symposium on Ecohydraulics. Aquatic Habitats: Analysis and Restoration, vol. 1, pp. 205-212.

Gustard, A., 1992. Analysis of river regimes. In: Calow, P., Petts, G. (Eds.), The Rivers Handbook, vol. 1. Blackwell Scientific Publications, London, UK, pp. 29-47.

Gutiérrez Elorza, M. 1994. Introducción a la geomorfología Espanoola. In: Geomorfología de España. Rueda, Madrid, pp. 1-24.

Hancock, M.A., Bunn, S.E., 1997. Population dynamics and life history of Paratyo australiensis Kemp, 1917 (Decapoda: Atyidae) in upland rainforest streams. South-Eastern Queensland, Australia. Mar. Freshwater Res. 48, 361-369.

Hannah. D.M. 1998. Meltwater Generation and Drainage within a Small Glacierized Basin in the French Pyrenees. Unpublished Ph.D. Thesis, University of Birmingham.

Hannah, D.M., Smith, B.P.G., Gumell, A.M., McGregor, G.R., 2000. An approach to liydrograph classification. Hydrol. Process. 14, 317-338.

Harris, N.M., Gumell, A.M., Hannah, D.M., Petts, G.E., 2000. Classification of river regimes: a context for hydroecology. Hydrol. Process. 14, 2831-2848.

Humphries, P., 2002. River regulation and fish larvae: variation through space and time. Freshwater Biol. 47, 1307-1331.

Hynes, HBN., 1970. The ecology of stream insects. Ann. Rev. Entomol. 15, 25-42.

Kalkstein, L.S., Tan, G., Skindlov, JA., 1987. An evaluation of three clustering procedures for use in synoptic climatological classifications. J. Climate Appl. Meteorol. 26, 717-730.

lytle, D.A., Poff, L.N., 2004. Adaptation no natural flow regime. Trends Ecol. Evol. 19 (2), 94-100.

Mahoney, J.M., Rood, S.B., 1998. Streamflow requirements for cottonwood seedling recruitment - an interactive model. Wetlands 18, 634-645.

Marchetti, M.P., Moyle, P.B., 2001. Elfects of flow regime on fish assemblages in a regulated California stream. Ecol. Appl. 11, 530-539.

Melcher, A., Schmutz, S., Haidvogl, G., 2007. Spatially based methods to assess the ecological status of European fish assemblage types. Fish Manage. Ecol. 14, 453463.

Nilsson, C., Berggren, K., 2000. Alterations of riparian ecosystems caused by river regulation. Bioscience 50 (9), 783-792.

Nilsson, C., Reidy, CA., Dynesius, M., Revenga, C., 2005. Fragmentation and flow regulation of the world's large river systems. Science 308, 405-408.

olden, J.D., Poff, N.L., 2003. Redundancy and the choice of hydrologic indices for characterizing streamflow regimes. River Res. Appl. 19, 101-121.

Petts, G.E., 1984. Impounded rivers. Perspectives for Ecological Management. John Wiley 8 Sons, Chichester, UK. p. 326.

PofT, N.L., Allan, J.D., 1995. Functional organization of stream fish assemblages in relation to hydrological variability. Ecology $76(2), 606-627$. 
Poff, N.L, Ward, J.V., 1989. Implications of streamflow variability and predictability for biotic community structure: a regional analysis of streamflow pattems. Can. J. Fish Aquat. $5 \mathrm{ci}, 46,1805-1818$.

Poff, N.L., Allan, J.D., Bain, M.B., Kar, J.R, Prestegaard, K.l., Richter, B.D., Sparks, R.E., Stromberg. J.C., 1997. The natural flow regime. Bioscience 47 (11), 769-784.

Poff, N.L., Richter, B.D., Arthington, A.H., Bunn, 5.E., Naiman, R.J., Kendy, E., Acreman, M., Apse, C., Bledsoe, B.P., Freeman, M.C., Henriksen, J., Jacobson, R.B., Kennen, J.G., Merrit, D.M., óKeeffe, J.H., Olden, J.D., Rogers, K., Tharme, R.E., Warner, A., 2010. The ecological limits of hydrologic alteration (ELOHA): a new framework for developing regional environmental flow standards. Freshwater Biol. 55, 147-170.

Richter, B.D., Baumgartner, J.V, Powell, J., Br'aun, D.P., 1996. A method for assessing hydrologic alteration within ecosystems. Conserv. Biol. 10, 1163-1174.

Rivas Martínez, S., Díaz, T.E., Fernández-González, F., lzco, J., Loidi, J., Lousa, M., Penas, A. 2002. Vascular plant communities of Spain and Portugal. Itinera Geobotánica 15, 1-2.

Ruiz. J.M., 1998. Desarrollo de un modelo hidrológico conceptual distribuido de simulación continua integrado con un SIG. Tesis doctoral. Universidad Politécnica de Valencia.

Sanz. E., 1996. Springs in 5pain: classification according to their flows and lithologies and their hydraulic contributions. Ground Water 34 (6), 1033-1041.
Spanish Ministry of Environment, 2006. Inventario de Presas Españolas. Ministerio de Medio Ambiente, Madrid, España.

Téme2,J.R., 1977. Modelo matemático de transferencia de precipitación-aportación. Asimel.

Rood, 5.B., Mahoney. J.M., 1990. Collapse of riparian poplar forests downstream from dams in western prairies: probable causes and prospects for mitigation. Environ. Manage. 14, 451-454.

Vannote, R.L., Minshall, G.W., Cummis, K.W., Sedell, J.R., Cushing, C.E., 1980. The river continuum concept. Can. J. Fish Aquat. Sci. 37, 130-137.

Verdin, J.L., Verdin, J.P. 1999. A topological system for delineation and codification of the Earth's river basins. J. Hydrol. 218, 1-12.

Ward, J.V., Stanford, JA., 1979. The Ecology of Regulated Streams. Plenum Press, New York, EEUU, p. 1979.

Wilby. R.l., 1993. The influence of variable weather patterns on river water quanticy and quality. Int. J. Climatol. 13, 447-459.

Lhttp://www.cedex.es>. Centro de Estudios y Experimentación de obras Públicas (Centro de Estudios Hidrográficos). Ministerio de Medio Ambiente y Medio Rural y Marino y Ministerio de Fomento.

<http:/fwww.chebro.es>, Confederación Hidrográfica del Ebro. Ministerio de Medio Ambiente y Medio Rural y Marino. 